JOPAT Vol 19(2), 398 - 409, July - Dec. 2020 Edition

ISSN2636 - 5448. Https://dx.doi.org/10.4314/jopat.v19i2.5

\title{
Preliminary Evaluation of the Acute and Sub-Acute Anti-Inflammatory Activities of Aqueous and Butanol Leaf Fractions of Olax subscorpioidea Oliv. (Olacaceae).
}

\author{
Odoma Saidi, ${ }^{1,2 *}$, Zezi A. Umar, ${ }^{3}$ Danjuma N. Muhammed, ${ }^{3}$ Ahmed Abubakar ${ }^{4}$ Magaji, M. \\ Garba, ${ }^{3}$ and Munir A. Sani. ${ }^{5}$ \\ ${ }^{1}$ Department of Pharmacology and Therapeutics, Kogi State University, Anyigba, Nigeria. \\ ${ }^{2}$ Department of Pharmacology and Toxicology, Kampala International University, Uganda. \\ ${ }^{3}$ Department of Pharmacology and Therapeutics, Ahmadu Bello University, Zaria, Nigeria. \\ ${ }^{4}$ Department of Pharmacognosy and Drug Development, Ahmadu Bello University, Zaria. Nigeria. \\ ${ }^{5}$ Department of Veterinary Surgery and Radiology, Ahmadu Bello University, Zaria, Nigeria.
}

\begin{abstract}
Olax subscorpioidea (Oliv.) leaf is widely used as a traditional remedy for pain, reduction of small tumors, edema, painful swellings, and other inflammatory conditions. Its anti-inflammatory potential in experimental animals has been documented. Furthermore, an anti-inflammatory assay guided fractionation showed that the aqueous and butanol leaf fractions were the most active. This study is aimed at investigating further, the acute and sub-acute anti-inflammatory potentials of the aqueous and butanol leaf fractions in mice and rats.
\end{abstract}

Carrageenan induced paw edema in rats, xylene induced ear edema in mice, and cotton pellet induced granuloma in rats were the models employed for the studies. For each of the methods, four randomly-selected groups of animals $(n=5 / 6)$ were orally administered with distilled water ( 1 $\mathrm{ml} / \mathrm{kg}$ ), aqueous or butanol fraction $(1,000 \mathrm{mg} / \mathrm{kg}$ ) and standard drugs (acetylsalicylic acid [ASA] $300 \mathrm{mg} / \mathrm{kg}$ or dexamethasone, $1 \mathrm{mg} / \mathrm{kg}$ ).

The aqueous and butanol fractions each showed significant $(p<0.01)$ inhibition of ear swelling, the fractions also significantly $(p<0.05, p<0.01)$ decreased the paw edema, and significantly $(p$ $<0.01)$ inhibited the granuloma formation.

The result of the study suggests that aqueous and butanol leaf fractions of Olax subscorpioidea are effective against acute and sub-acute inflammation.

Keywords: Carrageenan, Cotton-pellet granuloma, Inflammation, Olax subscorpioidea, Xylene.

*Corresponding Author, (email: odoma.s@ksu.edu.ng, Tel: +2348027547778)

(C)2007 The authors. This work is licensed under the Creative Attribution 4.0 International license. 


\section{INTRODUCTION}

Inflammation is the body's immune system's response to infection and injury [1]. It helps to repair and heal damaged tissues, and to defend the body against external invaders in the form of viruses and bacteria [2]. Acute inflammation is a short term response, characterized by redness, swelling, heat, pain, and loss of function; as it returns the body to a stable system. But, when an abnormal condition is sustained, it leads to chronic inflammation [1]; and this has been implicated in almost all chronic diseases, such as cancer, cardiovascular diseases, arthritis, inflammatory bowel syndrome, atherosclerosis and autoimmune diseases [35]

Steroidal and non-steroidal antiinflammatory drugs are among the most commonly prescribed drugs in the management of both acute and chronic inflammatory conditions [6]. However, the currently used agents are prone to evoking serious adverse reactions [7]. Side effects such as gastrointestinal tract (GIT) irritation, blood disorders, liver damage, renal damage, tinnitus, and hypersensitivity reactions, have significantly limited their use [8]. This justifies the search for new anti-inflammatory substances from the array of available natural products; with fewer side effects and better efficacy.

Medicinal plants and their by-products have been used for ages to treat different kinds of acute and chronic inflammatory diseases. Olax subscorpioidea is one of such medicinal plants and it has wide patronage. It is a shrubby plant, a member of the family Olacaceae, and distributed widely in African tropics with numerous uses. Traditionally, the root has been used for the management of cancer, pregnancy-associated fat, rheumatism, and constipation $[9,10]$. The leaf has also been used in the management of swelling, pain, and yellow fever $[10,11]$. The crude methanol extract, aqueous, butanol, and hexane leaf fractions were reported to possess phytochemicals such as alkaloids, carbohydrates, cardiac glycosides, flavonoids, saponins, steroids, and tannins $[11,12]$.

Previously, the anti-inflammatory activity of the methanol crude leaf extract of $O$. subscorpioidea has been reported by our group [11]. We also reported that the aqueous and butanol leaf fractions were more efficacious than other fractions in a bioactivity guided fractionation study [12]. The current study is aimed at assessing the acute and sub-acute anti-inflammatory 
activities of the aqueous and butanol leaf fractions. Acute anti-inflammatory activity was studied in carrageenan-induced paw edema in rats and xylene induced ear edema models in mice. The cotton pellet induced granuloma in rats model was used to study the sub-acute anti-inflammatory activity.

\section{MATERIALS AND METHODS}

\section{Collection and Identification of Plant.}

O. subscorpioidea leaves were collected from a farm in Anyigba, Kogi State, North Central Nigeria. The identification was done by Dr. E. I. Aigbokhan, a plant taxonomic with the Department of Biological Sciences, Kogi State University, Anyigba, Kogi State, Nigeria. A voucher specimen (KSUH-2772013-01) was deposited in the herbarium for future reference.

\section{Extraction and Fractionation.}

The extraction and fractionation were carried out according to a standard method [13]. The leaves of $O$. subscorpioidea were shade dried for several days till constant weight was achieved. The dried leaves were pulverized with mortar and pestle to achieve a fine powder. About one thousand grams $(1 \mathrm{~kg})$ of the powder was extracted exhaustively with aqueous-methanol (20-80, v/v) using a soxhlet apparatus, the extract was then concentrated on a water bath $\left(50^{\circ} \mathrm{C}\right)$. About $100 \mathrm{~g}$ of the methanol extract was suspended in water and successively partitioned with hexane, ethyl-acetate, and butanol to afford the corresponding fractions. The residual aqueous and the butanol fractions were removed by placing fractions, individually, on a water bath $\left(50^{\circ} \mathrm{C}\right)$. Each fraction was sealed in a bottle container and stored in a desiccator before use. Solutions of each of the fractions were freshly prepared with distilled water before each study.

\section{Laboratory Animals}

Adult Wistar Rats (140-170g) and Balb/c Mice (20-30g) were obtained from the Animal House facility of the Department of Pharmacology and Therapeutics, Ahmadu Bello University (ABU), Nigeria. The animals were kept under standard environmental conditions and fed with standard diet and water ad libitum. The approval for the experiments was given by the Ethical Committee of the Department of Pharmacology and Therapeutics, ABU, Nigeria (protocol number: DAC/IWOT/137/14). The experiments were carried out following the criteria outlined in the Guide for the Care and Use of Laboratory Animals [14]

\section{Carrageenan-induced edema in rats}

Randomly-selected four groups of rats $(\mathrm{n}=6)$ were orally administered with distilled water ( $1 \mathrm{ml} / \mathrm{kg})$, aqueous or butanol fraction $(1,000$ 
$\mathrm{mg} / \mathrm{kg}$ ) and acetylsalicylic acid (ASA, 300 $\mathrm{mg} / \mathrm{kg}$ ). Sixty minutes post-treatment, each rat was injected with $0.1 \mathrm{ml}$ of $1 \%$ carrageenan into the plantar surface of rat's right hind paw [15]. The paw diameter was measured using the cotton thread method [16] at times $0,1,2,3$, and 4 hours after the injection of carrageenan. The increase in paw diameter (paw edema volume) for each rat was calculated as the difference in paw diameter before carrageenan injection and after carrageenan injection at each time interval, while the percent inhibition of edema was calculated for each group with respect to its vehicle-treated control group by the following relationship:

Mean increase in paw volume of control - Mean increase in paw volume of treated Mean increase in paw volume of control $\times 100$

\section{Xylene induced ear edema}

Randomly selected four groups of mice $(\mathrm{n}=6)$ were orally administered with distilled water (10 $\mathrm{ml} / \mathrm{kg}$ ), aqueous or butanol fraction $(1,000 \mathrm{mg} / \mathrm{kg})$, and dexamethasone (1 $\mathrm{mg} / \mathrm{kg}$ ). One hour post-treatment, $30 \mu \mathrm{L}$ of pure xylene was applied to the inner surface of the mouse's right ear to induce edema [17]. Sixty minutes post edema induction, each mouse was euthanized under chloroform anesthesia, and both ears were immediately cut off and weighed on an analytic balance.
The difference between the intact (left) ear and the xylene-insulted (right) ear was recorded. Percentage inhibition of the ear edema was calculated relative to the left ear

Cotton pellet-induced granulation formation in rats (sub-acute inflammation) Male rats were divided into four groups $(n=5)$. Cotton pellet granuloma was produced by the method previously described by Winter and Porter [18]. The groin region of the rat was shaved under aseptic conditions, then, through a single needle incision, a sterile pre-weighed cotton pellet $(50 \mathrm{mg}$ ) soaked in distilled water $(0.2 \mathrm{~mL})$ containing streptomycin $(0.13 \mathrm{mg})$ and penicillin $(0.1$ $\mathrm{mg}$ ), was implanted subcutaneously in the groin under ketamine $(15 \mathrm{mg} / \mathrm{kg})$ anesthesia. Distilled water $(1 \mathrm{ml} / \mathrm{kg})$, aqueous or butanol fraction $(1,000 \mathrm{mg} / \mathrm{kg})$, or ASA $(300 \mathrm{mg} / \mathrm{kg})$ were administered orally for nine (9) consecutive days from the day of cotton pellet implantation. On day 10, the cotton pellet was dissected out, weighed, and dried at $60{ }^{\circ} \mathrm{C}$ until the weight remained constant. The difference in the weight of the cotton pellet before and after implantation was recorded and considered as granuloma tissue deposit. The difference in the body weights of the rats for the first and the last day of the experiments was also recorded

Statistical Analysis 
Values were expressed as mean \pm standard error of the mean (mean \pm SEM). The difference in mean was analyzed using one way and repeated measure ANOVA followed by Tukey's post-hoc test for Multiple Comparison using the Graph Pad Prism (statistical) software, version 7. The differences between means were considered significant when $p \leq 0.05$.

\section{RESULTS}

\section{Carrageenan-induced edema in rats}

The fractions and standard drug significantly $(p<0.05, p<0.01, p<0.001)$ decreased paw edema due to carrageenan (Figure 1a). The standard drug had a better anti-inflammatory activity compared to the fractions, with a maximum inhibition of $60.04 \%$, at the 4 th hour. This is followed by the aqueous fraction with a maximum inhibition of $44.16 \%$ at the 4th hour. The butanol fraction possesses the least anti-inflammatory activity with a maximum inhibition of $41.55 \%$ at the 4th hour (Figure 1b).

\section{Xylene induced ear edema}

A significant $(p<0.01)$ inhibition of ear edema was observed in all the treated animals (Figure 2). The butanol fraction had the highest inhibition (34.9\%) of edema, followed by the standard drug (32.66\%) then the aqueous fraction (27.96\%).

\section{Sub-acute inflammation}

The results of the sub-acute inflammatory test are shown in Table 1. The plant fractions and ASA demonstrated significant inhibitory activity on the weight of granuloma. The butanol fraction and ASA had significant $(p$ $<0.001)$ inhibitory effects on the granuloma formation compared to the aqueous fraction $(p<0.01)$. The butanol fraction had the highest inhibitory effect with $42.49 \%$ and $61.39 \%$, followed by ASA with $41.35 \%$ and $50.63 \%$ then the aqueous fraction with $23.64 \%$ and $35.44 \%$ on the wet and dried granuloma respectively.

\section{Effects of the extracts on rats' body weight}

The effects of the test drugs and the standard drug are presented in Table 2. There is no statistically significant difference in weight gain in the groups treated with the fractions when compared with the negative control group. But, the group treated with the standard drug had a significant $(p<0.05)$ reduction in the weight gain when compared with the negative control.

\section{DISCUSSION}

Previously we reported that the crude methanol leaf extract, aqueous, butanol, and hexane leaf fractions of Olax subscorpioidea possess anti-inflammatory activities [11, 12]. Currently, the aqueous and butanol leaf fractions are being investigated for acute and sub-acute anti-inflammatory activities using 
the dose with the best anti-inflammatory response $(1,000 \mathrm{mg} / \mathrm{kg})$ from our previous study.

Cotton pellet granuloma study is a sub-acute inflammation model that is widely used to determine the proliferative constituents of chronic inflammation [18]. The weight of the wet cotton pellets is related to proliferative material and the weight of the dry pellets is related to the amount of granulomatous tissue [19]. Cotton pellet granuloma tends to mimic the chronic inflammation caused by nonmicrobial and non-degradable pathogens. In this model, a non-immunological type of inflammation is observed and it is mediated by the activation of inflammatory mediators such as kinins [20]. Kinins cause both vasodilatation and increase vascular permeability in the early stages of inflammation [21]. NSAIDs exact their antiproliferative activity by decreasing granuloma tissue, preventing the occurrence of the collagen fiber, and suppressing mucopolysaccharides [19]. Thus, the results of the present study suggest the fractions' ability to inhibit sub-acute inflammation.

The reduction in weight gain caused by acetylsalicylic acid may be due to the ability of salicylates to rapidly reduce circulating triglycerides and or free fatty acids in obese rats and humans with type 2 diabetes by the activation of AMP-activated protein kinase (AMPK) [22].

The xylene ear edema model distinguishes non-steroidal anti-inflammatory drugs (NSAIDs) from steroidal anti-inflammatory agents [7]. It is sensitive to steroids and less sensitive to NSAIDs [23]. After the topical application of xylene, signs of acute inflammation are detected by severe vasodilation, edema, changes of the skin, and infiltration of inflammatory cells which causes the increased thickness of the ear tissues [23, 24]. Steroids exert their antiinflammatory effect by inducing the synthesis of a group of proteins (lipocortins). Lipocortins suppress the activation of phospholipase A2, thereby decreasing the release of arachidonic acid and the production of pro-inflammatory eicosanoids [25]. Thus, the results of the present study suggest that the plant might have inhibited the acute inflammation induced by xylene by decreasing the release of arachidonic acid and the production of pro-inflammatory eicosanoids.

Carrageenan induced rat's paw edema is the most widely used animal model for evaluation of anti-inflammatory property of medicinal plants [15], as it is not known to be antigenic and is devoid of apparent systemic effects [23]. Carrageenan induced edema 
gives a biphasic response. The first phase response is believed to be due to the release of serotonin, histamine, and bradykinin on vascular permeability and the second phase response is due to the overproduction of prostaglandin in tissues [26]. The ability of the fractions to inhibit rats' paw edema may be due to inhibition of inflammatory mediators such as prostaglandins, histamine, and serotonin.

Based on these findings, it may be inferred that the aqueous and butanol leaf fractions of O. subscorpioidea both possess acute and sub-acute anti-inflammatory activities. These results further confirm the folkloric use of the plant in the management of inflammatory diseases. Further investigations are anticipated to identify the active components responsible for its observed pharmacological activities.

\section{Acknowledgments}

The authors are thankful to the technical staff of the Department of Pharmacology and Therapeutics, Ahmadu Bello University, Zaria, for their technical support during the study.

\section{REFERENCES}

1. Medzhitov R (2008). Origin and physiological roles of inflammation. Nature. 454: 428-435.
2. Chen L, Deng H, Cui H, Fang J, Zuo Z, Deng J, Li Y, Wang X, Zhao L (2018). Inflammatory responses and inflammationassociated diseases in organs. Oncotarget. 9(6): 7204-7218.

3. Viljoen A, Mncwangi N, Vermaak I (2012). Anti-inflammatory Iridoids of Botanical Origin. Curr Med Chem. 19(4): 2104-2127.

4. Ricciotti E, FitzGerald GA (2011). Prostaglandins and inflammation. Arteriosclerosis, Thrombosis and Vascular Biology. 31: 986-1000.

5. Luo P, Wong YF, Ge L, Zhang ZF, Liu Y, Liu L, Zhou H (2010). Anti-inflammatory and Analgesic Effect of Plumbagin through Inhibition of Nuclear Factor-kB Activation. JPET. 335: 735-742.

6. Yazmín RC, Vivian MC, Sonia JD, Yohani PG, Ambar OY, Daisy CQ, Rosa MF (2011). Effects of D-002 on xylene-induced oedema in ear of mice. Revista CENIC, Ciencias Biológicas. 42(1): 13-16.

7. Agbaje EO, Fageyinbo MS (2012). Evaluating Anti-Inflammatory activity of aqueous root extract of Strophanthus hispidus DC (Apocynaceae). International Journal of Applied Research in Natural Products. 4(4): 7-14.

8. Mishra D, Ghosh G, Kumar PS, Panda PK (2011). An Experimental Study of Analgesic Activity of Selective Cox-2 Inhibitor with 
Conventional NSAIDs. Asian Journal of Pharmaceutical and Clinical Research. 4(1): 78-81.

9. Ogunmefun OT, Gbile ZO (2012). An Ethnobotanical Study of Anti-Rheumatic Plants in South-Western States of Nigeria. Asian Journal of Science and Technology. 4(11): 063-066.

10. Okoli RI, Aigbe O, Ohaju-Obodo JO, Mensah JK (2007). Medicinal Herbs Used for Managing Some Common Ailments among Esan People of Edo State, Nigeria. Pakistan Journal of Nutrition. 6(5): 490-496.

11. Odoma S, Zezi AU, Danjuma NM, Ahmed A (2014). Analgesic and anti-inflammatory Properties of Methanol Leaf Extract of Olax subscorpioides Oliv (Olacaceae) in Mice and Rats. Journal of Pharmacology and Tropical Therapeutics. 4(1): 29-37.

12. Odoma S, Zezi AU, Danjuma NM, Ahmed A (2015). Analgesic and Anti-Inflammatory Activities Guided fractionation of Olax Suscorpioidea Leaf Extract in Mice and Rats. Nig. Journ. Pharm. Sci. 14(1): 23-35.

13. Kupchan SM, Britton RW, Ziegler MF, Sigel CW (1973). Bruceantin, a new potent antileukemic simaroubolide from Brucea antidysenterica. Journal of Organic Chemistry. 38: 178-179.

14. Clark JD, Gebhart GF, Gonder JC, Keeling ME, Kohn DF (1997). The 1996 Guide for the Care and Use of Laboratory Animals. ILAR Journals. 38(1): 41-48.

15. Winter CA, Risley EA, Nuss GW (1962). Carrageenan induced edema in hind paw of the rat as an assay for anti-inflammatory drugs. Proceedings of the Society for Experimental Biology and Medicine. 111: 544-547.

16. Bamgbose SOA, Noamesi BK (1981). Studies on Crytolepine II: Inhibition of carrageenan-induced oedema by crytolepine. Planta Medica. 42: 392-396.

17. Agbaje EO, Adeneye AA, Adeleke TI (2008). Anti-nociceptive and antiinflammatory effects of a Nigerian polyherbal tonic (PHT) extract in rodents. Afr J Compl Alt Med. 5(4): 399-408.

18. Winter CA, Porter CC (1957). Effect of alteration in side chain upon antiinflammatory and liver glycogen activity of hydrocortisone esters. J. Am. Pharma. Ass. Sci. 46(197): 515- 519.

19. Verma S, Ojha S, Raish M (2010). Antiinflammatory activity of Aconitum heterophyllum on cotton pellet-induced granuloma in rats. Journal of Medicinal Plants Research. 4(15): 1566-1569.

20. Sur TK, Biswas TK, Ali L, Mukherjee B (2003). Anti-inflammatory and anti-platelet aggregation activity of human placental extract. Acta Pharmacol Sin. 24(2): 187-192. 
21. Elango V, Carolin O, Raghu PS (2012). Antiinflammatory activity of the flower extracts of Solanum nigrum in Rats. Hygeia Journal for Drugs and Medicines. 4(1): 59-62.

22. Steinberg GR, Dandapani M, Hardie DG (2013). AMPK: mediating the metabolic effects of salicylate-based drugs? Trends Endocrinol Metab. 24(10): 481-487.

23. Vetriselvan S, Subasini U, Velmurugan C, Muthuramu T, Shankar J, Revathy (2013). Anti-Inflammatory Activity of Cucumis Sativus Seed in Carrageenan and Xylene Induced Edema Model Using Albino Wistar Rats. International Journal of Biopharmaceutics. 4 (1), 34-37.
24. Kim HD, Cho HR, Moon SB, Shin HD, Yang KJ, Park BR, kim HJ, Lee HS, Ku SK (2007). Effects of beta-glucan from Aureobasidium Pullulans on acute inflammation in mice. Arch Pharm Res. 30: 323-328.

25. Craig CR, Stitizel RE (1997). Modern Pharmacology with clinical application, 5th edition.

26. Bhalke RD, Pal SC (2012). AntiInflammatory and Antinociceptive Activity of Pterospermum Acerifolium Leaves. Asian Journal of Pharmaceutical and Clinical Research. 5 (2): 23-26. 


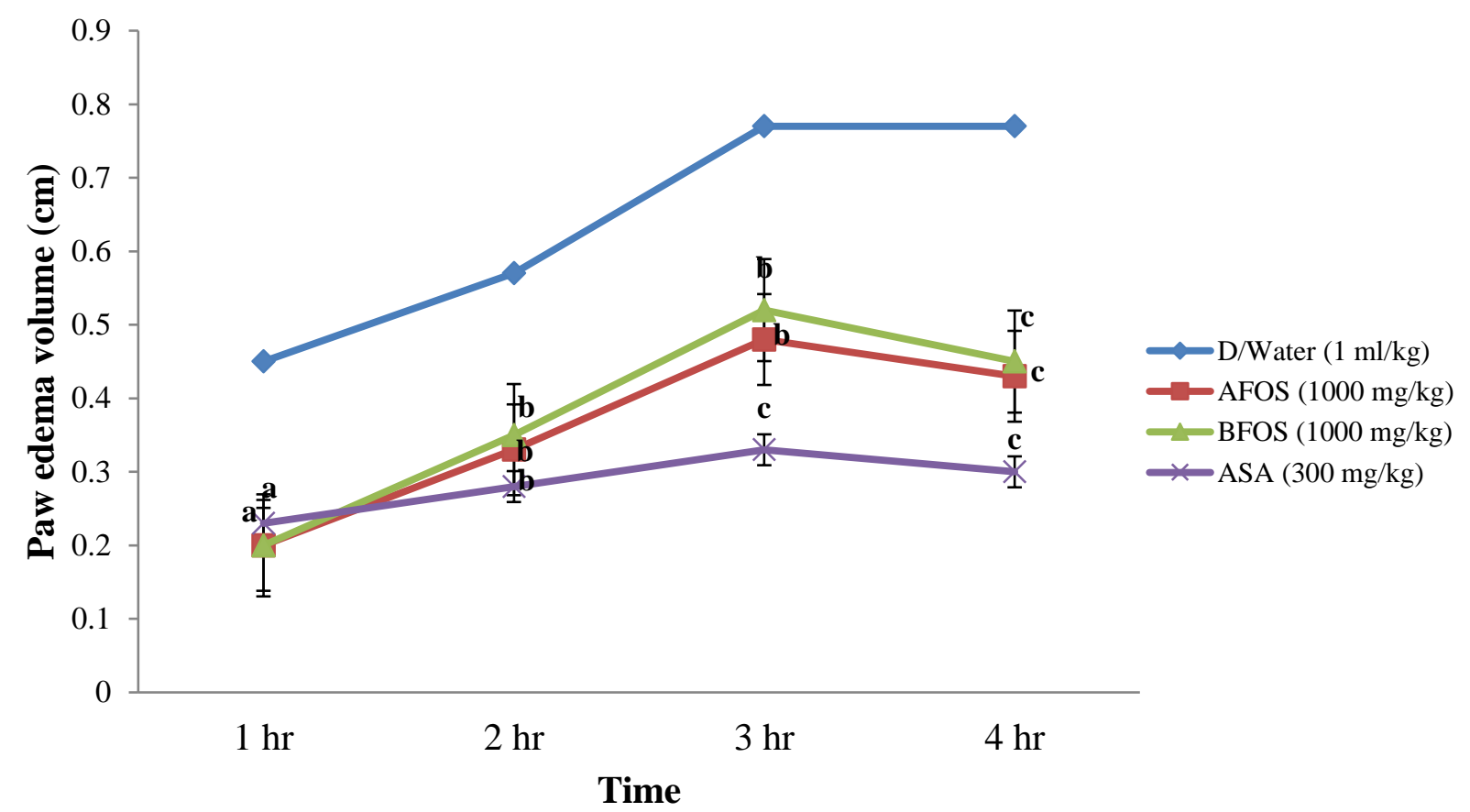

Figure 1a: Effect of aqueous and butanol leaf fractions of Olax subscorpioidea on carrageenan induced inflammation. $\mathrm{a}=p<0.05, \mathrm{~b}=p<0.01, \mathrm{c}=p<0.001$ versus distilled water. AFOS (aqueous fraction), BFOS (butanol fraction) and ASA (acetylsalicylic acid), $\mathrm{n}=6$. 


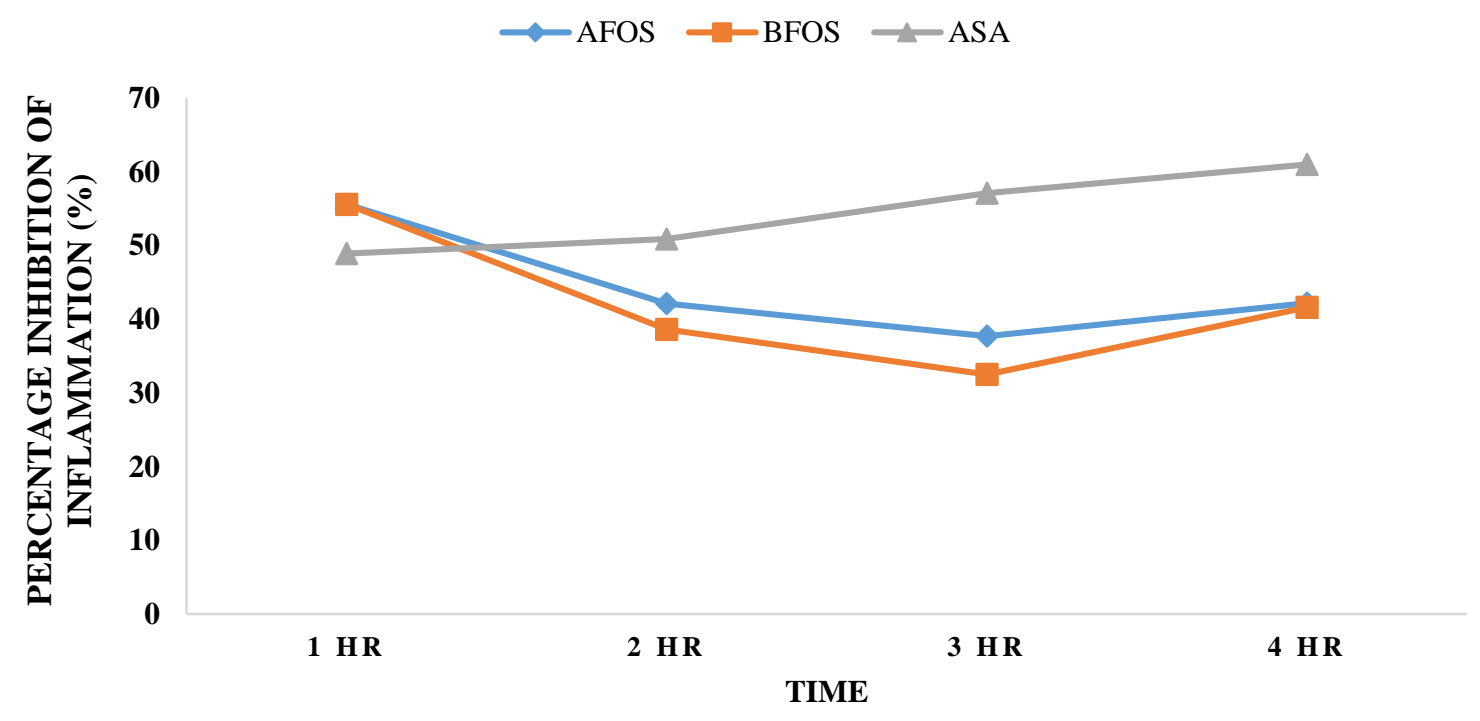

Figure 1b: Percentage inhibition of inflammation by the leaf fractions of Olax subscorpioidea and the standard drug. AFOS (aqueous fraction), BFOS (butanol fraction) and ASA (acetylsalicylic acid), n=6.

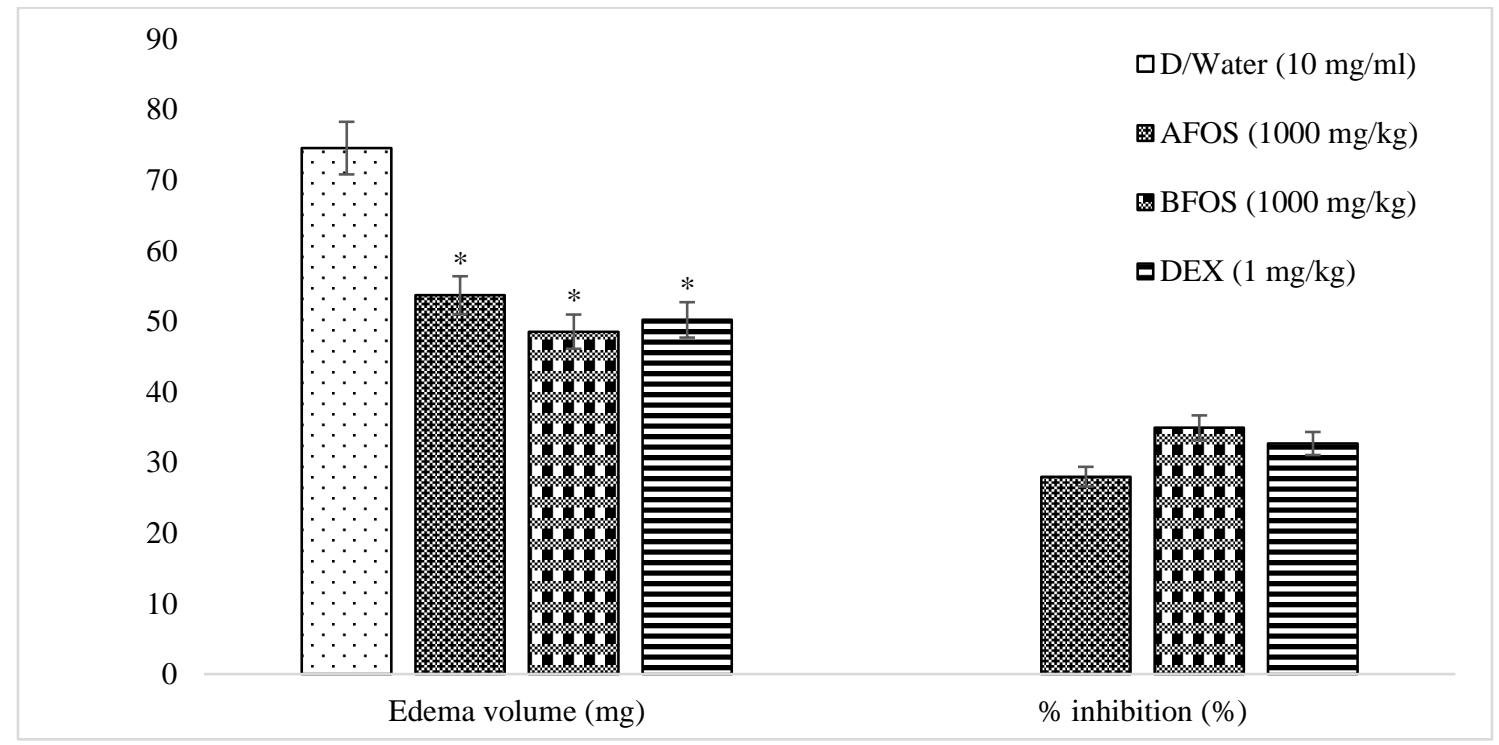

Figure 2: Effect of aqueous and butanol leaf fractions of Olax subscorpioidea on xylene-induced ear edema in mice. ${ }^{*} p<0.01$ versus distilled water. AFOS (aqueous fraction), BFOS (butanol fraction) and Dex (dexamethasone) $n=6$. 
Table 1: Effect of aqueous and butanol leaf fractions of $O$. subscorpioidea on sub-acute inflammatory model in rats

\begin{tabular}{|c|c|c|c|c|}
\hline & $\begin{array}{l}\text { Wet granuloma } \\
\text { weight (mg) }\end{array}$ & $\begin{array}{l}\text { Percentage } \\
\text { inhibition of } \\
\text { granuloma }(\%)\end{array}$ & $\begin{array}{l}\text { Dry granuloma } \\
\text { weight (mg) }\end{array}$ & $\begin{array}{l}\text { Percentage } \\
\text { inhibition of } \\
\text { granuloma }(\%)\end{array}$ \\
\hline Distilled water & $438.20 \pm 14.87$ & & $63.20 \pm 2.46$ & \\
\hline AFOS $1000 \mathrm{mg} / \mathrm{kg}$ & $334.60 \pm 18.42 *$ & 23.64 & $40.80 \pm 2.18^{*}$ & 35.44 \\
\hline BFOS $1000 \mathrm{mg} / \mathrm{kg}$ & $252.00 \pm 16.30^{* *}$ & 42.49 & $24.40 \pm 4.62 * *$ & 61.39 \\
\hline ASA 300 mg/kg & $257.00 \pm 16.9 * *$ & 41.35 & $31.20 \pm 4.32 * *$ & 50.63 \\
\hline
\end{tabular}

Table 2: Effect of aqueous and butanol leaf fractions of $O$. subscorpioidea on rats' body weight

\begin{tabular}{lllll}
\hline \multicolumn{1}{c}{ Group } & Dose $(\mathbf{m g} / \mathbf{k g})$ & \multicolumn{3}{c}{ Body Weight $(\mathbf{g})$} \\
\cline { 3 - 5 } & & Initial & Final & Gain \\
Distilled water & & $143.4 \pm 5.33$ & $167.2 \pm 4.66$ & $23.8 \pm 3.68$ \\
& & & & \\
AFOS & 1,000 & $149.4 \pm 8.90$ & $166.0 \pm 9.72$ & $16.6 \pm 2.11$ \\
BFOS & 1,000 & $146.8 \pm 10.15$ & $165.4 \pm 10.26$ & $18.6 \pm 4.46$ \\
ASA & 300 & $145.2 \pm 14.47$ & $155.2 \pm 5.40$ & $10.0 \pm 2.59 *$ \\
\hline$p<0.05$ versus & distilled & water. & AFOS (aqueous & fraction), BFOS (butanol fraction) and ASA \\
(acetylsalicylic acid), $\mathrm{n}=5$. & & &
\end{tabular}

